\title{
Using Technology-Nested Instructional Strategies to Enhance Student Learning
}

\author{
Angela Lumpkin, PhD \\ Professor and Chair of the Department of Health, Exercise, and Sport Sciences \\ Texas Tech University \\ Rebecca M. Achen, PhD \\ Assistant Professor of Sport Management in the School of Kinesiology and \\ Recreation \\ Illinois State University \\ Regan K. Dodd, PhD \\ Assistant Professor in the Department of Health, Physical Education and Recreation \\ Missouri Western State University
}

Students today expect the use of technology in their classes, rather than have to listen to less-than-engaging lectures. College students are connected electronically and incessant technology consumers. As a result, they may prefer the infusion of technologies to help them learn and enjoy the process of learning, rather than

having to listen exclusively to lectures. To investigate this, the authors solicited student perceptions to assess the importance of learning through technology-nested instructional strategies. Student perceptions give direction to and affirm the benefits of instructional strategies that increase student motivation to engage more actively in their learning. Based on quantitative and qualitative responses through action research in multiple courses, students perceive their learning as more engaging and enjoyable when technology-nested instructional strategies are infused into their classes.

Accountability for student learning has become the new norm in higher education. While teachers have been recognized as significant determinants in student learning, Bean (2011), Brookfield (2006), Davis (1993), Diamond (2008), McKeachie, Svinicki, and Hofer (2011), and Umbach and Wawrzynski (2005) claimed teachers cannot rely exclusively on class lectures because today's students expect use of technology and engaging activities. Malm and Defranco (2011-2012) concluded, "The next generation of students will not just be concerned about if technology is used, but rather how it is incorporated into the educational experience" (p. 404). Technology will serve as a catalyst to student engagement with content.

Yazedjian and Kolkhorst (2007) argued that unless students were forced to break out of the anonymity and inactivity of large classes, many of them resisted embracing course content and persisted in doing only the minimum. Absent any change, students cheated themselves of opportunities to collaborate with and learn from classmates, improve critical thinking and oral and written communication skills, and prepare more effectively for future jobs requiring interdependence and practical application of knowledge. Incorporating technology-based strategies has become one highly effective approach, especially benefiting visual and interactive instructional strategies, including learning management systems (LMSs), carefully designed slides developed using PowerPoint presentation software, an interactive review game, online blogs, two types of classroom response systems, and video clips. In developing this action research project in several courses, the authors carefully designed, implemented, and reflected on the use of these learning strategies and their impact on student perceptions of their learning.

The purpose of this study was to gather student perceptions of technologynested learners, for challenging students to engage more actively with course content (DeBourgh, 2008; Patterson, Kilpatrick, \& Woebkenberg, 2009). 


\section{Review of Literature}

This review of literature includes brief descriptions of the use of an LMS, PowerPoint slides, blogs, classroom response systems, and video clips. These technologies have been found to enrich and extend learning and actively engage students.

A university's provision of an LMS along with staff to support its use has encouraged and facilitated faculty members' use of instructional technologies. Malm and Defranco (2011-2012) suggested, however, that this was just the first step.

With the near-universal adoption of LMS platforms by colleges and universities, the time has come to shift the focus of conversation from whether faculty use the LMS to the more difficult and important questions of how these systems are impacting the student learning experience. (p. 410)

They also concluded that while these systems have been used pervasively, there was almost no evidence to verify how they were used and whether they impacted student learning.

Debevec, Shih, Mei-Yau, and Kashyap (2006) suggested PowerPoint slides provided a structure for lectures and discussions to help students focus and organize course material. Clark (2008) commented how PowerPoint slides focused students' attention, partially because watching and listening were preferred to just listening. She concluded, "The key element in the use of PowerPoint as a presentation tool is its potential to increase and maintain student interest and attention to the lecture when combined with active teaching and student involvement" (p. 39).

Debevec et al. (2006) reported their students often used an LMS in class preparation and study routines and were not deterred from attending class, compared to students who utilized an LMS less frequently. Slides posted on an LMS allowed students to view them electronically or use printed copies for taking aligned notes during lectures as well as in studying for tests. Clark (2008) also described how PowerPoint slides stimulated interest, improved note-taking, and promoted higher-order thinking (p. 39). As such, students are challenged to engage more deeply with the content by asking and answering questions to construct new knowledge.

In another use of an LMS, students were provided with blog prompts and required to post responses based on their understanding of assigned readings. The best blog prompts, Bean (2011) posited, "require students to respond knowledgeably to some part of course content but then to add their own views and experiences" (p. 209). Student discussions using blogs have been shown to facilitate student learning (Cheng \& Chau, 2011). They reported blogs enabled students to learn and expand the meaning of terms, revise co-constructed knowledge, and apply newly co-constructed knowledge in collaborative ways. Also, they found blogs helped students construct knowledge at a higher collaborative level.

Sevian and Robinson (2011) stated that use of a classroom response system, specifically clickers, helped teachers discover students' misconceptions, assess their preparedness, gauge the understanding of concepts, poll opinions to fuel debates, elicit discussion, and identify students who needed additional help. They found use of clickers increased the quality and quantity of participation, promoted learning, provided immediate and accurate feedback about what students did and did not understand, and stimulated critical thinking. DeBourgh (2008) concurred and concluded that increased student participation resulted "in high-level application and synthesis of complex concepts, and supports skill development for advanced reasoning" (pp. 86-87). Additionally, the use of classroom response systems possibly resulted in greater student enjoyment (Stowell \& Nelson, 2007) and engagement (Patterson et al., 2009). 
Videos have been found to enhance key course content (Wright \& Abell, 2011). Hoover (2006) found video clips were learning devices as well as attitude enhancers, especially for first- and second-year students, since many students are visual learners. That is, students remembered more of what they saw than what they heard. Doyle (2008) emphasized how pictures and images helped students remember what they were learning. Hoover (2006) concluded that video clips broke up the monotony of largely auditory lectures and assisted students' understanding of concepts, as long as the teacher offered pre- and postcontextual information to frame key concepts. Cooper and Robinson (2000) supported the benefits of using audiovisual presentations and offered how the effectiveness of using video clips improved when informal discussions were conducted before and after presentations to focus students' attention on the most important points.

Several authors supported the use of technology-nested strategies because they positively impacted student learning. Use of LMS, PowerPoint slides, blogs, classroom response systems, and video clips have been shown across multiple disciplines to engage students more actively and challenge them to think more critically as they learned and constructed new knowledge. But, what do students think

...it was determined student perceptions should be sought to support decisions of when to use or not to use technologies to enhance learning. about technology-based strategies? Little evidence exists about how students perceive the relationship between technologybased strategies and their learning (Komarraju \& Karau, 2008; Lumpkin, Achen, \& Dodd, 2015). While engaged students are the ideal, it is difficult to tell, based on body language and unsolicited comments, if students value instructional strategies. Because the authors wanted to have evidence of whether students valued expanded use of technologies in teaching, the purpose of this action research project was to gather student perceptions about whether these instructional strategies benefited their learning. Using the authors' classes as case studies, the authors collected student perceptions of several technology-based strategies in their courses across multiple content areas and levels of students.

\section{Method}

This work investigated student perceptions of the use of technology-based classroom activities and their perceptions about the impact of these strategies on their learning. A mutual interest in improving and enhancing student learning prompted the evaluation of multiple classroom learning strategies rooted in technology and identification of ways to utilize these strategies. Through this discussion, it was determined student perceptions should be sought to support decisions of when to use or not to use technologies to enhance learning.

\section{Participants}

Students in four undergraduate courses and one graduate course were asked to participate in the study by taking an author-designed survey at the end of the fall 2012 semester. One graduate class, taking a required course to complete their graduate degrees in sport management, was surveyed $(N=27)$. A total of 153 undergraduate students across four courses completed the survey. One of the undergraduate courses was an introductory course that was required of students to enter the sport management major. It consisted of mostly freshmen and sophomores; however, students across campus could also take the course as an elective. Another undergraduate course was an upper-level core course for sport management majors and consisted of primarily juniors and seniors. At a second university, sophomores, juniors, and seniors enrolled in a course required for all physical education majors pursing a concentration in health and exercise science 
were surveyed. The final course was an elective for upper-class physical education majors as well as a variety of other students.

\section{Materials}

Teaching at two universities, the authors used an LMS, PowerPoint slides, one or two classroom response systems, video clips, and an interactive review game. Blogs were designed and implemented by two of the authors. One type of classroom response system, Poll Everywhere, was used by each author, while one also used an additional classroom response system, Lino, with a graduate course.

Numerous learning materials placed on the LMS were designed to facilitate the achievement of student learning outcomes. Students were encouraged to utilize all course materials, and especially the PowerPoint slides, to expand and support understanding of key content.

Blogs encouraged students to complete assigned readings, respond to prompts, and engage in discussions with classmates. Ideally, through blogging, students gained deeper understanding of course material and applied information from assigned readings to practical situations. When using blogs, groups of 6 to 10 students facilitated learning from and with one another. Prompts or questions related to assigned readings posted on the LMS elicited responses from students, who use specific examples from readings to support their responses, contribute new perspectives about topics to the group, and demonstrate critical inquiry in their responses.

Using a template originally developed at Rutgers University, the authors incorporated a technology-based, interactive review game (i.e., Jeopardy-like) in undergraduate courses to help students review for tests. To create each interactive review game, 31 answers and questions were developed. Completion of one review game during class took 20-25 minutes. Students either formed groups or competed individually and were asked to raise their hands prior to responding. Students were required to put away tablets, laptops, and not use their notes. Each author displayed the answers in each category from the lowest to highest point value. If students were in groups, they discussed possible questions and chose their responses or the correct questions to match the answers provided. All students received points if they knew the correct questions. After each interactive review game was used for review, it was made available on the LMS to help students study for tests.

One example of a classroom response system, which unlike clickers cost students nothing, is Lino. The use of Lino, an online canvas service, enabled students to anonymously express opinions and view classmates' responses immediately to help facilitate discussions based on differing perspectives. After opening a Lino account (http://en.linoit.com), questions were developed about issues and posted for viewing during class. Using their smart phones, laptop computers, or tablets, students clicked on a hyperlink for each question provided on the LMS, which opened a Lino canvas with a teacher-initiated question. Students' responses appeared as "sticky notes" on the canvas and were rearranged or grouped by the teacher to facilitate discussions.

Use of Poll Everywhere, an online classroom response or polling tool, enabled real-time responses from students via their smart phones, tablets, or laptop computers. After each of the authors set up a free (which allows 40 responses per question; unlimited responses require a purchase) Poll Everywhere account, questions developed on the Poll Everywhere website allowed students to answer electronically individually or in groups and to view responses immediately. By downloading a free presentation application onto the classroom computer, responses to each question placed on Poll Everywhere and linked directly to PowerPoint allowed real-time responses to appear in a graphic format (for true/false or multiple choice questions) or a scrolling list of open-ended responses. Through Poll Everywhere, students' understanding was assessed, and students' anonymous opinions on controversial issues were solicited. 
Video clips were used to enrich and extend student learning through timely and informative visual technology. Professional organizations, media outlets, and commercial videos were searched to obtain video clips to supplement course content. YouTube provided another useful resource, but its use required careful review to ensure quality and appropriateness of content. Links to video clips were embedded within PowerPoint slides, which permitted students to review video clips or view them if absent from class.

\section{Procedure}

In conjunction with regular course evaluations, student perceptions were measured through an anonymous, author-designed questionnaire. The questionnaire asked students to respond about the degree $(0=$ not at all; $1=$ sometimes; and 2 = often) of positive impact on their learning for each technologynested strategy. Additionally, students were asked to record the open-ended comments at the bottom of this questionnaire. A student volunteer collected completed questionnaires in an envelope and returned them to each author, allowing the teacher to be absent during questionnaire completion. Quantitative data and students' qualitative feedback are provided in the results.

Quantitative data from all four undergraduate classes were compiled, and percentages for each learning strategy were calculated as composites. Students' qualitative comments were reviewed by each author and organized by learning strategy. Then, each author reviewed student comments and grouped them based on themes found in students' word choice (for example, fun, interesting, helped me learn). Then all three authors reviewed the comments for reporting. Comments representing each unique student sentiment supporting the quantitative findings were reported.

\section{Results}

The study collected quantitative and qualitative data from undergraduate and graduate students to examine which of the technology-nested instructional strategies positively impacted their learning. Over $80 \%$ of undergraduate and $88 \%$ of graduate students rated each strategy as 'often' or 'sometimes' positively impacting their learning. Students' ratings of each instructional strategy are listed separately in Table 1 for undergraduate and graduate students.

Table 1

Student Ratings of the Impact on Learning of Technology-Nested Instructional Strategies

\begin{tabular}{|c|c|c|c|}
\hline & Not at All & Sometimes & Often \\
\hline \multicolumn{4}{|c|}{ Undergraduate Student Ratings } \\
\hline Blogs $(n=123)$ & $13 \%$ & $43 \%$ & $44 \%$ \\
\hline $\begin{array}{l}\text { Interactive Review Game ( } n= \\
151)\end{array}$ & $7 \%$ & $31 \%$ & $62 \%$ \\
\hline $\begin{array}{l}\text { Learning Management System ( } n \\
=55 \text { ) }\end{array}$ & $0 \%$ & $44 \%$ & $56 \%$ \\
\hline Poll Everywhere $(n=149)$ & $17 \%$ & $53 \%$ & $30 \%$ \\
\hline PowerPoint Slides $(n=55)$ & $0 \%$ & $2 \%$ & $98 \%$ \\
\hline Video Clips $(n=55)$ & $2 \%$ & $44 \%$ & $55 \%$ \\
\hline \multicolumn{4}{|c|}{ Graduate Student Ratings } \\
\hline $\begin{array}{l}\text { Learning Management System ( } n \\
=27)\end{array}$ & $4 \%$ & $37 \%$ & $59 \%$ \\
\hline Lino $(n=26)$ & $12 \%$ & $42 \%$ & $46 \%$ \\
\hline Poll Everywhere $(n=27)$ & $4 \%$ & $59 \%$ & $37 \%$ \\
\hline
\end{tabular}




\begin{tabular}{lccc} 
PowerPoint Slides $(n=27)$ & $11 \%$ & $33 \%$ & $56 \%$ \\
Video Clips $(n=27)$ & $0 \%$ & $15 \%$ & $85 \%$ \\
\hline Note: Undergraduate N = 153; Graduate N = 27
\end{tabular}

Students also provided open-ended comments about their perceptions of the technology-nested instructional strategies (see Table 2). Comments are organized by learning strategy and undergraduate and graduate students.

Table 2

Students' Comments about Technology-Nested Instructional Strategies

Undergraduate Students' Comments

Learning management system

- "Helped me learn the material more"

Slides developed using presentation software

- $\quad$ "Because it clearly explains what everything is and so they were very helpful to refer to when I was uncertain about something"

- $\quad$ "They summarized the information clearly and concisely and helped me study effectively"

- "The way I learned the best in combination with you lecturing" Group blogs

- "Although I didn't like doing them they were pretty helpful"

- "Forced us to read articles and articulate thoughts and concepts"

- "Helped incorporate the readings"

- $\quad$ "Because they really didn't come up on the tests and were more for making sure you actually read. I still learned a lot from the blogs and they were informational"

- $\quad$ "Forces you to do the reading and critically think on the topic"

- "They were difficult, but doesn't mean I didn't learn from them"

- "I liked the weekly engagement in real world situations"

- "It displayed real world application on perspective for the topics"

- $\quad$ "It required you to comprehend as well as analyze new material every time"

- "Had to read article to understand, help me learn"

- $\quad$ "Because they were usually helpful article[s] and it helped understanding them by writing about them"

- "It helped me to talk and understand the readings"

- $\quad$ "They made you apply what you learned" Jeopardy

- "While doing the reading made you pay better attention"

- "Class involvement and learned"

- "Helped with review"

- "Because it was a fun way to review for the tests"

- "Something fun but still learned from it"

- "Helped me learn and know what was important"

- $\quad$ "Actually integrated material helped learn. Posting on Blackboard helped as well"

- $\quad$ "I thought they were a very beneficial review"

- "Help learn, more relaxed"

- $\quad$ "They were entertaining but were still learning"

- "Fun way to review as class"

- "Quizzing us on info and having fun with it was helpful"

- $\quad$ "Fun because the questions were straightforward and I know I needed to know them in order to do well on tests"

- " "It was fun and easy way to study"

- $\quad$ "Helped me put all we learned into something fun, made it easier for me to 
learn"

- $\quad$ "It helped us understand what was the most important information and what you (i.e., professor) thought was important"

- "It got the class to interact and work together"

- "Because I like the competition aspect of the game"

- "Helpful before exams. Involved the whole class"

- $\quad$ "They were questions based on what she taught us, therefore, made the test easier and less stressful"

\section{Poll Everywhere}

- "Those were fun because you got the other people's response"

- "It was fun, interactive, and useful"

- "I like the interactive part of class"

- "Interesting to see what everyone else is thinking"

- "Was interesting to anonymously vote or poll on information then discuss Video clips preferences, usually was funny"

- "The clips are fun and easy to watch"

Learning management system

\section{Graduate Students' Comments}

- "Concrete learning with topical research"

- "Course material well-selected and gave well-rounded understanding" Slides developed using presentation software

- "Well-done, made issues clear"

$\underline{\text { Lino }}$

- "Funny to see different responses and discussion was good"

- "Interactive learning, made class more interesting" Video clips

- "Able to see others thoughts and opinions"

- "Real life experiences/examples"

- $\quad$ "I'm a visual learner"

- "Real world examples that we can apply"

- $\quad$ "Nice to hear what experts say on popular subjects"

An examination of the comments made by undergraduate students suggested they found the use of technology-nested strategies enjoyable and beneficial to their learning. They commented positively on the use of an LMS and PowerPoint slides, stating these helped them learn more and improved the clarity of the material. Additionally, students' comments about blogs, another strategy facilitated on the LMS, suggested students found them helpful in the learning

From a positive perspective, students appreciated the convenient, easy access to a fully developed LMS... process by making them read, think critically, and apply what they learned. With regard to interactive review games, undergraduate students believed their use increased peer interaction during class, helped them understand what material was most important, and allowed them to enjoy class. Students' comments about the use of Poll Everywhere emphasized the importance of learning from classmates and interactivity in class. Also, students appreciated the use of videos in class because it gave them real-world examples and kept their attention.

Graduate students perceived that in-class technologies enhanced the learning environment by giving them a clearer picture of course concepts and helping them learn even outside of class. Specifically, graduate students perceived the use of Lino positively, stating it allowed for interaction and its uniqueness held their attention. Finally, graduate students felt that videos provided examples that expanded on key content and engaged them during class. 


\section{Discussion}

While research in teaching and learning has discussed the impact of technology-based strategies on learning from the teacher's perspective, students' evaluations of these strategies are lacking. Student perceptions are valuable for evaluating learning strategies because students who enjoy learning will learn more (Komarraju \& Karau, 2008). The purpose of this study is to examine student perceptions of the use of technology-nested learning strategies and determine if students' believe they learn more when these strategies are used as current literature suggests that they do.

\section{Learning Management System}

LMSs on college campuses are ubiquitous, with millions of dollars dedicated to supporting faculty members' and students' use of these systems. As Malm and Defranco (2011-2012) questioned, however, are these systems impacting student learning? Students provided qualitative and quantitative evidence that they believed the LMS and other technologies helped enhance their learning. From a

It is important to note, however, that positive perspective, students one possible negative about using an appreciated the convenient, easy LMS could occur if students rely too access to a fully developed LMS, heavily on their teachers to provide many preferred to use course everything relative to the course. materials posted on the LMS to learn on their own time and individual pace. This should encourage faculty members to take the time to organize course materials and post them online so students can easily find information outside of class. It is important to note, however, that one possible negative about using an LMS could occur if students rely too heavily on their teachers to provide everything relative to the course, such as lecture notes and review questions and answers, making students feel they do not have to attend class to achieve passing grades. This further illustrates the need to engage students in class and challenge them by using instructional strategies that force them to participate.

\section{PowerPoint Slides}

Students especially liked the availability of PowerPoint slides on an LMS to guide note taking during class presentations and while studying for tests. This confirmed the conclusions of Debevec et al. (2006) and Clark (2008) about how PowerPoint slides increased student focus and attention during class. When students commented on the availability and use of PowerPoint slides, overall comments were positive. For example, students described PowerPoint slides as detailed and helpful, stated how they made good use of and liked writing notes on these slides, and appreciated their availability online. Additionally, several stated they learned more because the PowerPoint slides were well-developed. This highlights the fact that students appreciate well-developed course content. So, teachers should consider how their course slides facilitate student learning. Additionally, teachers might clearly explain how the PowerPoint slides can serve as a framework to help guide their learning from lectures, textbooks, and other readings as well as remind students that not every slide will be discussed in class.

\section{Blogs}

One difficulty for many teachers is convincing students to read and apply what they read. Students commented that responding to blog questions helped them better understand assigned readings. Based on student comments and anecdotal evidence, the blogs were effective in motivating students to read, engage with, and understand assigned readings, as Bean (2001) also reported. Similar to Cheng and Chau (2011), the authors agreed that while students may not like 
responding to blogs, (i.e., it took time and thought), they were convinced they learned more by reading and writing about what they read. Also, the authors found the use of blogs became even more effective when students were provided with timely feedback and specific examples of quality student posts and when blog responses were used as discussion starters in

class. In comparing the positives and negatives, blogs contributed to student learning due to their investment of time in reading, thinking, and writing; still, many students would have preferred not to have to

Students enjoyed the variety of playing interactive review games to assess what they were learning or may not yet have learned.

respond to the blogs because of the out-of-class time and effort required. The authors concluded that greater engagement with content led to more learning even though blogs were the least liked instructional strategy used.

\section{Jeopardy-Like Game}

One of the most popular technology-nested instructional strategies was using an active learning, change-of-pace Jeopardy-like game to review for tests; plus students liked having these games placed on the LMS for further review. Students enjoyed the variety of playing interactive review games to assess what they were learning or may not yet have learned. Students also found these games to be fun and enjoyable, which kept them engaged and interested during class. The amount of time for each interactive review game seemed well spent in helping students self-assess their learning and review for tests. Undergraduate students overwhelmingly enjoyed engaging in the Jeopardy-like games because they were fun yet beneficial. There were not any negatives, other than the initial time it took to develop each game.

\section{Poll Everywhere and Lino}

Due to the cost of clickers, the authors instead took advantage of two free classroom response systems, with students expressing appreciation for not having to purchase expensive clickers. Overwhelmingly, students enjoyed using Poll Everywhere because it was interactive, occurred in real-time, and gave them immediate feedback about what they were or were not learning. They were asked to respond individually or in groups, with the latter facilitating interactions with classmates. Students commented that they enjoyed learning from their classmates and sharing their own thoughts on a wide range of topics, without feeling anxiety over speaking in front of a large group of their peers. No doubt, student participation and engagement increased through in-class polling, as Sevian and Robinson (2011), DeBourgh (2008), and Patterson et al. (2009) also reported. Another classroom response strategy, Lino, received very positive feedback from several graduate students as they indicated using Lino helped their learning and was enjoyable. The positives of using Poll Everywhere and Lino were that they were free, students received immediate feedback on their responses which in turn contributed to class discussions as students learned from each other, and the technology-based approach was a change-of-pace strategy used to teach and review content. Since use of these two response systems forced student participation, a few students expressed they would have preferred to sit passively rather than engage actively.

\section{Video Clips}

Comments from students indicated videos were interesting, enjoyable, and helpful to their learning. Overwhelmingly, punctuating class lectures with video clips to reinforce or extend key points was an effective instructional approach and addressed the need to meet the visual learning styles of many students, which 
Wright and Abell (2011) also found. Students appreciated the inclusion of video clips to inform their learning through real-world examples (Doyle, 2008). Almost all students liked the real-world applications and practicality shown through video clips to reinforce or expand their understanding of key concepts, which led to many positive comments about them. Video clips, however, add nothing to learning unless they are carefully chosen and connected specifically to what is taught or the key points to be reinforced visually.

When over $50 \%$ of undergraduate and graduate students rate a technology-based instructional strategy as often having a positive impact on their learning, this is strong evidence of their effectiveness, as the data in Table 1 verify. If a technology-based instructional strategy even sometimes has a positive impact on learning, its occasional use is supported. Through this action research project, the authors were strongly convinced students' comments and ratings supported the importance, and even essentiality, of continued use of technology-based instructional strategies. This action research project that used the authors' classes as case studies reaffirmed the use of LMS, PowerPoint slides, blogs, Jeopardy-like review games, Poll Everywhere, Lino, and video clips to positively impact student perceptions of their learning.

One limitation of this study is its exclusive use of sport and health classrooms, which could limit the generalizability of the findings. Researchers across disciplines should collaborate to use the same survey instruments and methods to study students' evaluation of technology-based learning strategies on their learning. Additionally, the results in this study are limited to students who chose to write anonymous, open-ended comments giving the authors no ability to follow up with students or probe students about the reasons they believe strategies do not positively impact their learning. This information is just as valuable as the reasons why they believe strategies do positively impact their learning. To examine this, researchers could conduct semi-structured interviews with students to gain a deeper understanding of why and how these strategies help them learn.

\section{Conclusion}

College students enjoy and value the use of technologies in their classes. The evidence illustrates how use of an LMS to organize and provide learning materials for students helps facilitate learning and active engagement with course content. Video clips add real-world examples and applications to further extend learning. Blogs are especially effective in holding students accountable for completing readings and focusing on learning because they must respond to prompts and provide specific examples from readings in their responses. Students seem to enjoy opportunities to share their opinions through classroom response systems, like Lino and Poll Everywhere, and thoroughly enjoy playing an interactive review game. Technology-nested strategies engage students actively in their learning and help reinforce information previously presented, especially as a change of pace punctuating traditional lectures.

Students' positive comments encourage the authors to continue to adapt and adopt technology-nested strategies to enhance learning. The authors remain committed to and desirous of increasing the infusion of technology-based instructional approaches in teaching. The positive results about student perceptions

Blogs are especially effective in holding students accountable for completing readings and focusing on learning because they must respond to prompts and provide specific examples from readings in their responses. adds to the literature by challenging other faculty to incorporate innovative technologies in their courses and then gather evidence of strengthened and expanded student learning in their classes. Through this process faculty can learn what technologies students perceive as beneficial to their learning as well as enjoyable. Most importantly, student perceptions are valuable in assessing technology-based strategies because students' 
decisions to attend class and actively participate are inevitably linked to the use of these technologies. When students enjoy the learning process in their courses, they are more likely to prepare for, participate in, and interact with disciplinary content.

\section{References}

Bean, J. C. (2011). Engaging ideas: The professor's guide to integrating writing, critical thinking, and active learning in the classroom ( $2^{\text {nd }}$ ed.). San Francisco, CA: Jossey-Bass.

Brookfield, S. D. (2006). The skillful teacher: On technique, trust, and responsiveness in the classroom ( $2^{\text {nd }}$ ed.). San Francisco, CA: Jossey-Bass.

Cheng, G., \& Chau, J. (2011). A comparative study of using blogs and wikis for collaborative knowledge construction. International Journal of Instructional Media, 38, 71-78.

Clark, J. (2008). PowerPoint and pedagogy: Maintaining student interest in university lectures. College Teaching, $56,39-45$.

Cooper, J. L., \& Robinson, P. (2000). Getting started: Informal small-group strategies in large classes. New Directions for Teaching and Learning, 81, 17-24.

Davis, B. G. (1993). Tools for teaching. San Francisco, CA: Jossey-Bass.

Debevec, K., Shih, Mei-Yau, \& Kashyap, V. (2006). Learning strategies and performance in a technology integrated classroom. Journal of Research on Technology in Education, 38, 293-307.

DeBourgh, G. A. (2008). Use of classroom "clickers" to promote acquisition of advanced reasoning skills. Nurse Education in Practice, 8, 76-87.

Diamond, R. M. (2008). Designing and assessing courses and curricula: a practical guide ( $3^{\text {rd }}$ ed.). San Francisco, CA: Jossey-Bass.

Doyle, T. (2008). Helping students learn in a learner-centered environment: $A$ guide to facilitating learning in higher education. Sterling, VA: Stylus Pub.
Hoover, D. S. (2006). Popular culture in the classroom: Using audio and video clips to enhance survey courses. The History Teacher, 39, 467-478.

Komarraju, M., \& Karau, S. J. (2008). Relationships between the perceived value of instructional techniques and academic motivation. Journal of Instructional Psychology, 35, 70-82.

Lumpkin, A., Achen, R. M., \& Dodd, R. K. (2015). Student perceptions of active learning. College Student Journal, 49 (1), 121-133.

Malm, E., \& Defranco, J. F. (2011-2012). Toward a student-centered measure of learning management system utilization. Journal of Educational Technology Systems, 40, 401-413.

McKeachie, W. J., Svinicki, M., \& Hofer, B. K. (2011). McKeachie's teaching tips: Strategies, research, and theory for college and university teachers $\left(13^{\text {th }}\right.$ ed.). Belmont, CA: Wadsworth.

Patterson, B., Kilpatrick, J., \& Woebkenberg, E. (2009). Evidence for teaching practice: The impact of clickers in a large classroom environment. Nurse Education Today, 30, 603-607.

Sevian, H., \& Robinson, W. E. (2011). Clickers promote learning in all kinds of classes - Small and large, graduate and undergraduate, lecture and lab. Journal of College Science Teaching, 40(3), 1418.

Stowell, J. R., \& Nelson, J. M. (2007). Benefits of electronic audience response systems on student participation, learning, and emotion. Teaching of Psychology, 34, 253-258.

Umbach, P. D., \& Wawrzynski, M. R. (2005). Faculty do matter: The role of college faculty in student learning and engagement. Research in Higher Education, 46, 153-184. 
Wright, D. G., \& Abell, C. H. (2011). Yazedjian, A., \& Kolkhorst, B. B. (2007). Using YouTube to bridge the gap Implementing small-group activities in between baby boomers and millennials. large lecture classes. College Teaching, Journal of Nursing Education, 50, 299- 55, 164-169.

300.

Angela Lumpkin is a professor and Chair of the Department of Health, Exercise, and Sport Sciences at the Texas Tech University. Previously, she served as Dean of the School of Education at the University of Kansas, Distinguished Visiting Professor at the United States Military Academy, Dean of the School of Education at State University of West Georgia, Head of the Department of Physical Education at North Carolina State University, and professor of Physical Education at the University of North Carolina at Chapel Hill. Angela is the author of 23 books and over 60 publications and delivered over 200 professional presentations.

Rebecca M. Achen is an assistant professor of sport management in the School of Kinesiology and Recreation at Illinois State University. She graduated with her PhD in sport management from the University of Kansas, where she also taught as a graduate teaching assistant. Prior to that, Rebecca received her master's degree from Winona State University in Educational Leadership with an emphasis in sport management. She has many years of work experience in higher education administration and sport marketing and sales.

Regan Dodd is an assistant professor in the Department of Health, Physical Education and Recreation at Missouri Western State University. She earned a PhD in health education from the University of Kansas, a Master of Business Administration from Baker University, a Master of Science in Education and a Bachelor of Science from Northwest Missouri State University. Prior to earning her doctorate, she served as an instructor of physical education and head men's and women's tennis coach at Baker University. 